\title{
A Universidade do Porto e as Universidades Brasileiras
}

\author{
Alberto Amaral \\ Reitor da Universidade do Porto no período de Dezembro de 1985 a Agosto de 1998 \\ https://doi.org/10.5628/rpcd.01.01.06
}

Escrever sobre as relações com as universidades brasileiras é para mim simultaneamente um prazer e uma dificuldade. Um prazer porque todo o percurso que a partir da primeira visita ao País irmão constitui uma sucessão de recordações extremamente gratas, aliadas ao êxito que foi a campanha de promoção da Universidade do Porto no Brasil. Uma dificuldade porque é difícil ser objectivo quando a razão se mistura constantemente com o coração. Porém, estou certo que os leitores perdoarão ao antigo reitor a mistura de alguma objectividade com a recordação um tanto emocional de alguns dos melhores momentos do passado. O estabelecimento de relações privilegiadas com os países de língua portuguesa sempre constituiu um objectivo da Universidade do Porto, tal como definido nos seus primeiros estatutos. No Plano de Desenvolvimento da Universidade do Porto, para o período de 1994/99, recomenda-se que seja feito um grande esforço para incrementar a cooperação com as instituições congéneres dos países de língua portuguesa, como um dos vectores para ganhar a aposta numa maior internacionalização da Universidade.

Pode dizer-se que a Universidade do Porto cumpriu cabalmente estes objectivos, sendo curioso notar que no que respeita ao Brasil foi uma escola recente da Universidade, a Faculdade de Ciências do Desporto e Educação Física, que representou um papel de excepcional relevo no estabelecimento de protocolos e na criação de relações estreitas com as universidades do País irmão.

As realizações foram imensas e estou certo que se as tentar enumerar extensivamente cometerei o inevitável pecado de me esquecer de algumas. Que me perdoem as dificuldades de memória de quem vem somando anos a uma vida cheia de recordações; como dizia o poeta Pablo Neruda, Confesso que Vivi! Certamente foram celebrados imensos protocolos com universidades brasileiras, alguns de carácter folclórico-turístico nunca produziram resultados visíveis, porém muitos resistiram ao passar dos anos e produziram resultados surpreendentes. Permitam-me que recorde, por exemplo, os inúmeros doutoramentos e mestrados obtidos por cidadãos brasileiros provenientes das mais diversas regiões. Ou os cursos de Verão que o Professor Daniel Bessa organizou durante anos, com êxito inegável, em cooperação estreita com a Universidade de Santa Catarina. Ou o Mestrado resultante da cooperação entre a Faculdade de Ciências do Desporto e de Educação Física da Universidade do Porto e a Universidade do Estado do Rio de Janeiro. $\mathrm{Ou}$ as iniciativas de teleconferências entre o Porto e Santa Catarina.

Se os docentes tiveram oportunidade de uma permuta importante com os seus colegas brasileiros, foram as oportunidades dadas aos alunos da Universidade do Porto que mais me entusiasmaram. Quanto não valerá em formação pessoal a possibilidade de um aluno de um curso médico fazer um estágio em doenças tropicais no Hospital Tropical de Manaus? Ou para um aluno de Biologia poder passar alguns meses nesse território mítico que é a Amazónia? Ou as digressões sempre acarinhadas (e recebidas com orgulho pelas comunidades portuguesas) do Orfeão da Universidade e de algumas equipas desportivas? Também não sei disfarçar a emoção que um reitor sente ao visitar uma universidade brasileira e ser 
cumprimentado por um docente brasileiro que se apresenta e diz com orgulho que esteve na Universidade do Porto, onde obteve o seu doutoramento! E o encontro com um professor da Universidade de Cuiabá, na orla desse imenso e inesquecível pantanal, entusiasta de um instrumento típico conhecido por "viola de cocho" que vem agradecer o contacto com a Fundação Gulbenkian que lhe possibilitou a obtenção de uma bolsa de estudos para se doutorar em Portugal?

Devo, também, relembrar o Programa ALPHA, criado pela UE para o desenvolvimento das relações com as universidades dos países da América Latina, o qual permitiu incrementar a ligação com as instituições brasileiras, por meio de reuniões de trabalho entre os Conselhos de Reitores das Universidades de Portugal e do Brasil. O Projecto Bracara, financiado por este programa, permitiu um estudo comparativo de sistemas de ensino superior da Europa e da América Latina, com particular relevo para os casos de Portugal e do Brasil, ao abrigo do qual se realizaram 5 conferências internacionais onde foram debatidos os grandes problemas das universidades.

Mas para além de todas estas realizações devo reconhecer que o êxito das iniciativas se ficou a dever na aposta em relações privilegiadas com um número limitado de instituições, nomeadamente com a Universidade de Santa Catarina, a Universidade do Estado do Rio de Janeiro, a Universidade do Amazonas e as universidades Federal e Estadual do Pernambuco.

Aposta que só foi ganha pela criação de relações pessoais de estreita amizade e de convergência de propósitos com alguns parceiros chave das universidades brasileiras. Que me perdoem os outros e que não mo levem à conta de ingratidão, mas não posso esquecer a nível universitário o Professor António Celso Alves Pereira (antigo reitor) e a Professora Nilcea Freire (antiga vice-reitora e actual reitora) da Universidade do Estado do Rio de Janeiro, o Professor Nelson Fraiji (antigo reitor) e o Professor Almir Liberato (pró-reitor) da Universidade do Amazonas, o Professor Mozart Ramos, actual reitor da Universidade Federal de Pernambuco e o grande amigo Professor Efrém Maranhão, antigo reitor da mesma universidade e actual Presidente do Conselho
Nacional de Educação do Brasil.

Fora do meio universitário é impossível esquecer o grande amigo Zeferino Costa ( e seu irmão Alberto), o tio Zeferino, esse verdadeiro embaixador da Universidade do Porto no Brasil, a quem tanto se fica a dever na promoção das relações entre Portugal e Brasil.

Porém, para mim pessoalmente, os acontecimentos mais marcantes foram a organização das três grandes exposições que tiveram lugar no Porto, em 1994, e em Manaus, em 1997. Para que a memória não me atraiçoe recorrerei a documentos que então escrevi. Em 1994 a Universidade do Porto organizou, em colaboração com as Universidades Federal o Pernambuco e do Amazonas (Manaus) duas exposições sobre temas brasileiros, a primeira sobre a Amazónia: "Memória da Amazónia: Etnicidade e Territorialidade”, centrada em torno do espólio da "Viagem Philosófica" de Alexandre Rodrigues Ferreira (1782/1791) e a segunda sobre as artes populares e eruditas do Nordeste brasileiro. As exposições foram inauguradas em 23 de Junho, com a presença do Presidente da República, Dr. Mário Soares, do Governador do Estado do Pernambuco, Dr. Joaquim de Freitas Cavalcanti, do Secretário de Estado do Turismo do Estado do Amazonas, Dr. Charles Belchieur, do Prefeito da Cidade do Recife, Jarbas Vasconcelos, do Presidente da Câmara do Porto, Fr. Fernando Gomes e de reitores de diversas universidades portuguesas e brasileiras.

A exposição Memória da Amazónia: Etnicidade e Territorialidade, centrada em torno do espólio da Viagem Philosóphica de Alexandre Rodrigues Ferreira (1783-1791) culminou todo o trabalho de cooperação entre as universidades do Porto e do Amazonas. Esta exposição teve um carácter inovador, ultrapassando a tradicional mostra de escritos, desenhos e artefactos produzidos e recolhidos, no século XVIII, pela expedição de Alexandre Rodrigues Ferreira, para desafiar os visitantes com a busca de uma análise crítica e de uma interpretação das transformações que decorrem desse passado longínquo até à realidade presente. A exposição "Memória da Amazónia” coloca em confronto o passado, evocado pelos escritos, desenhos e artefactos recolhidos no Séc. XVIII por Alexandre Rodrigues Ferreira, com a realidade 
presente dos povos indígenas que sobrevivem, hoje, nas mesmas regiões. E sobrevivem, apesar das compulsões do presente para que se "tornem civilizados", renunciando às suas formas tradicionais de agir e de pensar, o que desmente a imagem sobre eles criada, de "seres efémeros, em transição para a cristandade, a civilização, a assimilação, o desaparecimento.

A "Memória da Amazónia: Etnicidade e Territorialidade" reflectiu uma abordagem antropológica das transformações ocorridas nos últimos anos nas sociedades indígenas, as quais têm origem nesse confronto que se iniciou há cinco séculos entre "povos que aí habitavam há milhares de anos, com as suas múltiplas formas de vida, e dos que chegaram, invadiram e conquistaram, colonos, funcionários, missionários, militares"; confronto que era documentado nos três espaços em que se organiza a exposição que "correspondem a três tipos de situações de contacto interétnico na Amazónia do Brasil; e que podem estar e estão presentes desde o século XVI aos nossos dias: CHOQUE, TUTELA e AFIRMAÇÃO DE ETNICIDADE".

Mas esta Memória da Amazónia foi, também, testemunho da capacidade criadora das universidades, da sua vocação para o estudo das questões sem barreiras de línguas, culturas ou preconceitos, do seu valor como veículos privilegiados para o aprofundamento das relações entre países e culturas.

A exposição foi possível graças a essa grande cumplicidade que se estabeleceu entre instituições irmanadas no desejo de criar algo de belo e de exemplar. Forçoso é relembrar a contribuição dos espólios do Museu de Antropologia da Universidade de Coimbra, da Academia de Ciências de Lisboa, da Sociedade de Geografia de Lisboa e do Museu Nacional de Arqueologia e Etnografia. Aos comissários da exposição, Fernandes Dias, Eglantina Monteiro, Paulo Providência e Ângelo de Sousa, em representação de todos quantos contribuíram com o seu trabalho, ficam os agradecimentos por essa obra inesquecível. A exposição sobre as artes populares e eruditas do Nordeste brasileiro relança o debate dos limites entre arte e artesanato, as questões da arte popular e da arte erudita. Temas caros ao Porto, cidade fabriqueira, herdeira de artesanatos e manufacturas com passado medieval, alfobre de mesteres. A exposição permitiu ver obras de autores tão importantes como Bajado, Samico, Montez, Galdino, Salustino, Nuca, Cornélio, Laprovítera, Berison, Jordão, Baccaro, Mendes, Lopes, alguns ex-votos e, ainda, trabalho dos artífices do carnaval de Pernambuco.

Esta exposição é, igualmente, uma festa de celebração do encontro de duas cidades partilhando em comum a existência do rio e a presença do mar, mas cidades tão diversas onde, no entanto, nos sentimos sempre em casa, cidades irmãs de países irmãos, unidas pela história, pela língua e pela cultura.

De um lado o Porto, "cidade de granito, lavada de chuvas e amaciada de nevoeiros", cidade de contrastes, orgulhosa das suas tradições e ciosa da sua liberdade, cidade de actividade fervilhante, cidade comerciante e marinheira, cidade da cultura, debruçada sobre o rio e encostada ao mar, cidade, como nos diz Helder Pacheco, "de todos os fascínios, contradições e incongruências, que permanece, inconfundivel e única, na austera e conflituosa vocação da sua perenidade.

Do outro lado o Recife, "metade roubado ao mar, metade à imaginação", cidade protegida do mar pela própria natureza de onde retira o nome, cidade das pontes e dos canais, embelezada pelos seus rios, "conglomerado de gentes de todos os matizes, que se misturam a todos os instantes sem se atritarem, fruto de uma colonização humanística onde o homem sempre foi sua maior riqueza, cidade em jeito de criança aberta a todas as crenças. Até mesmo a crença de não ter fé. A fé, até de ter esperança. " (Edvaldo Arlego).

Esta exposição teve como curadores o artista plástico Sylvia Pontual e o arquitecto Moisés Andrade, ficando a montagem a cargo dos arquitectos Janete Costa, Mário Santos e Pedro Gadanho. A eles, como representantes desse grupo anónimo e entusiasta que transformou o sonhe em realidade, são devidos os agradecimentos da Universidade do Porto. Mal eu sabia, uma vez passada a tensão de todo o trabalho que permitiu o êxito destas iniciativas, que um desafio ainda maior estava para vir. O então reitor da Universidade do Amazonas, esse homem que ama como nenhum essa região única no mundo, teve o sonho de levar a Manaus a exposição Memória da 
Amazónia. Sonho que inicialmente parecia irrealizável. Mais tarde, por ocasião do doutoramento honoris causa do Presidente do Brasil, Dr. Fernando Henriques Cardoso, foi dado um passo determinante: os reitores das universidades de Porto, de Coimbra e do Amazonas assinaram um protocolo que previa a deslocação da exposição para o Brasil, protocolo que foi assinado pelos Presidentes Henrique Cardoso e Mário Soares como testemunhas.

O sonho realizou-se em 1997. Pelo caminho ficaram avanços e recuos, muitos obstáculos ultrapassados, algumas incompreensões e muitas amizades. Ainda me lembro das reuniões com o amigo Nelson Fraiji no Palácio da Presidência em Brasília, nos Ministérios da Educação e da Cultura brasileiros, com o Governador do Estado do Amazonas, com o Prefeito de Manaus... Sei lá, todas as portas foram usadas. Do meu lado sempre contei com os que sonharam comigo, em especial o Fernandes Dias e a Eglantina Monteiro.

Finalmente com a presença do Dr. Mário Soares, na altura já ex-presidente da República, do Ministro da Educação de Portugal, Professor Marçal Grilo, do Ministro da Cultura do Brasil, do Governador do Amazonas, de chefias índias e da inevitável multidão de notáveis foi feita a inauguração dessa exposição realizada no Palácio do Rio Negro, antiga sede do Governo do Amazonas. Palácio que foi recuperado para o efeito e que não podia ter melhor início de novas funções. No dia seguinte, nesse edifício esplendoroso que é a Ópera de Manaus, a Universidade do Amazonas selou o êxito da iniciativa com a concessão do doutoramento honoris causa ao Dr. Mário Soares.

Estas exposições foram, essencialmente, o resultado da colaboração de três Universidades, do Porto, Federal do Pernambuco e do Amazonas e mostram como estas instituições, herdeiras de uma tradição multissecular da procura de novos conhecimentos e da transmissão do conhecimento e da cultura, dotadas de uma grande capacidade criativa e de um inegável espírito de iniciativa, sempre defensoras de um grande espírito internacionalista, podem ser os veículos privilegiados para o aprofundamento das relações entre países e culturas.

Os universitários, por formação, têm o dever de estar permanentemente insatisfeitos com as situações estáticas, partindo sempre na busca de novas questões, a que não é alheia a capacidade de sonhar. Como dizia Fernando Pessoa "Triste de quem vive em casa/ Contente com o seu lar,/ Sem que um sonho, no erguer da asa,/ Faça até mais rubra a brasa/ da lareira a abandonar."

Mas, no fundo, para nós universitários, tal como dizia o poeta Agostinho Neto, o fundamental será o acto de "Criar, criar..." não esquecendo que o artista e o universitário devem transportar em si essa mesma contaminação, o vírus do inconformismo e a insatisfação face ao imobilismo. Sem o que não se cumprirá a Universidade.

Para terminar terei que referir a jóia da coroa. Com a comparticipação do Governo do Pernambuco, da Prefeitura do Recife, da Câmara Municipal do Porto e de empresários do Estado do Pernambuco está a ser construída, em terrenos da Universidade, a "Casa do Pernambuco no Porto”, instituição pensada nas tradições do Gabinete Português de Leitura do Recife, embora com ambições mais amplas; será um centro de difusão da cultura nordestina, um centro de negócios, um local de encontro das comunidades das duas cidades irmãs (Porto e Recife) e uma residência para professores visitantes e alunos de pós-graduação oriundos, preferencialmente, do Estado do Pernambuco.

Hoje, quando olho para trás, penso que, por vezes, corri riscos substanciais. Porém, os resultados obtidos na promoção do encontro dos dois Países e na contribuição do prestígio da Universidade do Porto mostram que valeu a pena. E assim posso repetir com a consciência tranquila: Confesso que Vivi! 